\title{
Transcription factor-based modulation of neural stem cell differentiation using direct protein transduction
}

\author{
Kristin Stock • Lars Nolden • Frank Edenhofer • \\ Tamara Quandel · Oliver Brüstle
}

Received: 4 January 2010/Revised: 16 February 2010/Accepted: 8 March 2010/Published online: 30 March 2010 (c) The Author(s) 2010. This article is published with open access at Springerlink.com

\begin{abstract}
In contrast to conventional gene transfer strategies, the direct introduction of recombinant proteins into cells bypasses the risk of insertional mutagenesis and offers an alternative to genetic intervention. Here, we explore whether protein transduction of the gliogenic transcription factor Nkx2.2 can be used to promote oligodendroglial differentiation of mouse embryonic stem cell (ESC)derived neural stem cells (NSC). To that end, a recombinant cell-permeant form of $\mathrm{Nkx} 2.2$ protein was generated. Exposure of ESC-derived NSC to the recombinant protein and initiation of differentiation resulted in a two-fold increase in the number of oligodendrocytes. Furthermore, Nkx2.2-transduced cells exhibited a more mature oligodendroglial phenotype. Comparative viral gene transfer studies showed that the biological effect of Nkx2.2 protein transduction is comparable to that obtained by lentiviral transduction. The results of this proof-of-concept study depict direct intracellular delivery of transcription factors as alternative modality to control lineage differentiation in NSC cultures without genetic modification.
\end{abstract}

Electronic supplementary material The online version of this article (doi:10.1007/s00018-010-0347-1) contains supplementary material, which is available to authorized users.

K. Stock $\cdot$ L. Nolden $\cdot$ F. Edenhofer

Stem Cell Engineering Group, Institute of Reconstructive Neurobiology, LIFE and BRAIN Center, University of Bonn and Hertie Foundation, Bonn, Germany

K. Stock · L. Nolden · F. Edenhofer · T. Quandel ·

O. Brüstle $(\square)$

Institute of Reconstructive Neurobiology, LIFE and BRAIN

Center, University of Bonn and Hertie Foundation,

Sigmund-Freud-Strasse 25, 53105 Bonn, Germany

e-mail: brustle@uni-bonn.de
Keywords Protein transduction - Transcription factors Neural stem cell · Neural differentiation .

Oligodendrocytes

\section{Introduction}

Controlled differentiation into neuronal and glial lineages is a key prerequisite for the biomedical application of neural stem cells (NSC). In addition to exposure to extrinsic growth and differentiation factors, expression of instructive transcription factors has been employed to modulate cell fate decisions. Viral transduction of the transcription factors Nurr1 and Lmx1a has recently been used to promote the differentiation of midbrain dopamine neurons from mouse embryonic stem cells (ESC) [1-3]. A central problem in most viral and non-viral gene transduction systems is random integration of the vectors in the host genome, which can result in insertional mutagenesis potentially leading to aberrant differentiation and tumor formation. On the other hand, direct intracellular delivery of bioactive proteins and nucleic acids is limited by low permeability of the eukaryotic cell membrane. Recently, the generation of cell-permeant proteins has emerged as a promising new avenue for intracellular protein transfer [4-6]. Transduction is enabled by linking the protein of interest to protein transduction domains (PTD), also designated cell-penetrating peptides (CPP). The short PTD from the transactivator protein (TAT) of HIV-1 [7-9], the viral protein 22 (VP22) of Herpes simplex virus [10] and the antennapedia homeoprotein of Drosophila [11, 12] have been fused to a variety of proteins, including cell cycle factors [13, 14], DNA recombinases [15, 16] and transcription factors [17-21]. Highly efficient delivery of biologically active proteins was reported for a wide variety 
of cultured cells including mouse [22] and human ESC [23] as well as neural precursor cells and post-mitotic neurons [24]. Although cell-permeant proteins have mainly been shown to work in vitro, their functionality was also demonstrated in vivo [25-29]. The mechanism of cellular uptake is not fully understood but appears to involve at least two cellular processes, endocytosis and direct membrane penetration $[30,31]$.

There is strong evidence that the molecular control of oligodendrocyte specification and differentiation from neural stem or progenitor cells is regulated by the transcription factors Olig1/2, Nkx2.2, Sox 9 and Sox10 [32] (Fig. 2a). Several studies have demonstrated that expression of the basic helix-loop-helix transcription factors Olig1 and Olig2 is required for oligodendrocyte lineage determination in vivo [33-35]. In addition, the highmobility transcriptional regulator Sox 10 and the homeodomain transcription factor $\mathrm{Nkx} 2.2$ have been proposed to directly regulate oligodendrocyte differentiation and myelin gene expression. Mutations of both genes result in a decreased number of oligodendrocytes in the CNS [36, 37]. These findings suggest that Sox 10 and Nkx2.2 cooperatively mediate the function of Olig2 to control oligodendrocyte differentiation and maturation. Conversely, expression of Nkx2.2 in combination with Olig2 can induce ectopic formation of mature myelin basic protein (MBP)-positive oligodendrocytes in embryonic chicken spinal cord [38]. Along this line, inducible expression of Olig2 has been used to promote the generation of oligodendrocytes from murine ESC [39] and transduction of human fetal neural precursors with an Olig2-encoding lentivirus induces their commitment towards an oligodendroglial fate in vitro and in vivo [40]. In human adult-derived NSC, co-transfection with Olig2 and Nkx2.2 or Sox10 and Nkx2.2 induces oligodendrocyte differentiation and maturation [41]. Thus, overexpression of transcription factors that play essential roles in oligodendrocyte development facilitate oligodendrocyte specification and differentiation in neural stem and progenitor cells.

In this study, we explore direct intracellular delivery of recombinant $\mathrm{Nkx} 2.2$ protein as an alternative tool to modulate and augment the differentiation of ESC-derived NSC into oligodendrocytes without genetic modification.

\section{Materials and methods}

Culture and differentiation of NSC

Clonally derived mouse ESC-derived NSC (line NS-5) were cultured according to Conti et al. [42]. Oligodendroglial differentiation was performed as described [43].
Briefly, cells were plated on polyornithin/laminin-coated dishes and proliferated in NSC expansion medium, which is composed of NS-A medium (Euroclone, Pero, Italy) plus N2 supplement (Invitrogen, Karlsruhe, Germany), $10 \mathrm{ng} / \mathrm{ml}$ fibroblast growth factor 2 (FGF2; Invitrogen) and $10 \mathrm{ng} / \mathrm{ml}$ epidermal growth factor (EGF; Invitrogen). For differentiation, this medium was replaced by DMEM/F12 (Invitrogen) supplemented with N2 (differentiation medium), and the cells were propagated for 4 days without FGF2 and EGF but in the presence of 3,3,5-tri-iodothyronine (T3; $30 \mathrm{ng} / \mu \mathrm{l}$; Sigma, Steinheim, Germany) and ascorbic acid (AA; $200 \mu \mathrm{M}$; Sigma).

Protein expression, purification and transduction

Recombinant Nkx2.2 fusion protein was expressed from a pTriEx1-based plasmid in E. coli. Briefly, Nkx2.2-specific primers were used to amplify the coding sequence from human $n k x 2.2$ cDNA clones (Open Biosystems, Huntsville, AL) by PCR reaction. The sequence was cloned between the AvrII and NheI sites of the pSESAME-C vector [17] to construct a fusion protein comprising the protein transduction sequence at the $\mathrm{C}$-terminus. The fusion protein was purified from the $E$. coli lysates using $\mathrm{Ni}^{2+}$ affinity chromatography, eluted and concentrated in a glycerol stock. For protein transduction the protein was diluted in cell culture medium. For most experiments the protein was used at a final concentration of $5 \mu \mathrm{g} / \mathrm{ml}$. Fresh protein was added every day. NSC were treated with protein during the last day of proliferation and throughout the subsequent 4-day growth factor withdrawal-induced differentiation in the presence of $\mathrm{T} 3$ and AA.

Labeling of recombinant protein

For tracking of transducible $\mathrm{Nkx} 2.2$, the protein was labeled with N-hydroxy-succinimide-rhodamine (NHSrhodamine, Pierce, Rockford, IL). To that end, $2.5 \mathrm{ml}$ of the recombinant protein $(200 \mu \mathrm{g} / \mathrm{ml})$ were mixed with $250 \mu \mathrm{l}$ NHS-rhodamine $(37 \mu \mathrm{g} / \mathrm{ml})$ and incubated for $2 \mathrm{~h}$ in darkness. The labeled protein was transferred onto a desalting column and eluted with PBS/DMEM high glucose (1:1). Protein concentration was quantified by Bradford staining (Bio-Rad, Cambridge, MA). The eluate was used immediately or divided into aliquots and frozen in a dry ice/ethanol bath and stored at $-80^{\circ} \mathrm{C}$. For application of the labeled protein on NSC, the cells were washed twice with PBS and incubated with NSC expansion medium containing the labeled protein $(50 \mu \mathrm{g} / \mathrm{ml})$. After $30 \mathrm{~min}$ the cells were washed three times with heparin $(0.5 \mathrm{mg} / \mathrm{ml}$, Sigma) to detach protein bound to the cell surface. Nuclei were visualized by Hoechst staining 
$\left(1: 1,000\right.$, Sigma) for $15 \mathrm{~min}$ at $37^{\circ} \mathrm{C}$, and the labeled protein was tracked using fluorescence microscopy.

Immunocytochemical analysis

For immunocytochemical analysis cells were fixed with $4 \%$ PFA for $10 \mathrm{~min}$ at room temperature. After washing in PBS, cells were blocked with 5\% normal goat serum in PBS and incubated overnight in $1 \%$ normal goat serum in PBS with the following primary antibodies: Olig2 (rabbit IgG; 1:3,000; Chemicon, Hofheim, Germany), Nkx2.2 (mouse IgG; 1:1,000; Thomas M. Jessell, Columbia University, New York), Sox10 (mouse IgG; 1:1,500; Michael Wegner, University of Erlangen-Nürnberg, Germany), Sox9 (rabbit IgG; 1:300; Chemicon), O4 (mouse IgM; 1:100; Chemicon), GFAP (rabbit IgG; 1:1,000; DAKO, Hamburg, Germany), NG2 (rabbit IgG; 1:75; Chemicon), bIII-tubulin (rabbit IgG; 1:1000; Covance, Denver, USA) and GFP (rabbit IgG; 1:500; Acris Antibodies GmbH, Hiddenhausen, Germany). For intracellular antigens, cells were permeabilized in PBS containing 0.1\% Triton X-100. Antigens were visualized using appropriate fluorochromeconjugated secondary antibodies applied for $1 \mathrm{~h}$ : goat antimouse IgM-Cy3 (1:250, Jackson Immuno Research, West Baltimore Pike, PA, USA), goat anti-mouse IgG-Alexa 555 (1:700, Invitrogen, Karlsruhe, Germany) and goat antirabbit IgG-Alexa 488 (1:800, Invitrogen). 4'-6-Diamidino2-phenylindole (DAPI, Sigma) was used for nuclear counterstaining. Labeled cells were preserved in Vectashield (Vector Laboratories, Burlingame, CA) and analyzed using a Zeiss fluorescence microscope. Quantitative analysis was carried out by counting the number of immunoreactive cells per total number of viable cells as determined by DAPI staining. Data for each marker are based on triplicate cultures with $\geq 20$ randomly chosen high power fields quantified for each staining.

\section{Western blot analysis}

For preparation of cell lysates NSC were washed twice with ice-cold PBS. Ice-cold lysis buffer $(50 \mathrm{mM}$ Tris- $\mathrm{HCl}$ $\mathrm{pH}=8,120 \mathrm{mM} \mathrm{NaCl}, 5 \mathrm{mM}$ EDTA, 0.5\% NP-40) containing protease inhibitors $(2 \mu \mathrm{g} / \mathrm{ml}$ aprotinin, $10 \mu \mathrm{g} / \mathrm{ml}$ leupeptin, $100 \mu \mathrm{g} / \mathrm{ml}$ phenylmethylsulphonyl fluoride; Sigma) was added, and cells were collected using a cell scraper. The cell suspension was centrifuged $(10 \mathrm{~min}$, $1,800 \mathrm{rpm}, 4^{\circ} \mathrm{C}$ ), the supernatant was discarded, and the cell pellet was resuspended in lysis buffer. After an incubation time of $15 \mathrm{~min}$, the lysates were centrifuged again $\left(15 \mathrm{~min}, 13,000 \mathrm{~g}, 4^{\circ} \mathrm{C}\right)$. The protein concentration in the supernatant was determined by Bradford analysis. From each sample $35 \mu \mathrm{g}$ in $2 \times$ SDS loading buffer was used for immunoblot analysis. To assess the stability of the recombinant $\mathrm{Nkx} 2.2-\mathrm{NTH}$ protein in culture medium, samples were taken from the medium at different time points. After centrifugation $40 \mu$ of the supernatant in $2 \times$ SDS loading buffer were used for immunoblot analysis. Extracts from the lysates or culture medium were separated on a $12 \%$ SDS-polyacrylamide gel and electroblotted onto nitrocellulose membranes (Amersham Bioscience, Freiburg, Germany). The blots were blocked with $5 \%$ fat-free milk powder in PBS/0.05\% Tween 20 and probed with primary antibodies to Nkx2.2 (mouse IgG, 1:200; Thomas M. Jessell, Columbia University, New York, NY) or PentaHis horseradish peroxidase (HRP) (Cell Signaling Technology, Danvers, MA) at $4{ }^{\circ} \mathrm{C}$ overnight. For detection of Nkx2.2 a HRP-conjugated secondary antibody (anti-mouse HRP; 1:3,000; Cell Signaling, Danvers, MA) was applied after washing for $1 \mathrm{~h}$ at RT. Signals were visualized with an enhanced luminol solution (SuperSignal System, Pierce, Rockford, IL).

\section{Lentiviral vector construction and transduction}

The lentiviral constructs are based on the commercially available pLenti6/V5 vector (Invitrogen). The Nkx2.2 transgene was cloned from a human $n k x 2.2$ cDNA clone (Open Biosystems, Huntsville, AL). The enhanced green fluorescent protein (EGFP) plasmid (pLVTHM) and the helper (pCMVDR8.91) and envelope (pMD2.G) plasmids were kindly provided by Didier Trono (Ecole Polytechnique Fédérale de Lausanne, Lausanne, Switzerland). The vector constructs contained the $\mathrm{Nkx} 2.2$ sequence coupled to EGFP via an IRES sequence or EGFP only as control. Transcription was driven by the constitutively active phosphoglycerate kinase (PGK) promoter. The vector also contained a Simian vacuolating virus 40 (SV40)-driven blasticidine-resistance gene for clonal selection.

The day before transduction, the target cells were passaged onto six-well plates to reach a density of $60-80 \%$ on the day of transduction $\left(0.8-1 \times 10^{6}\right.$ cells/well). For transduction, the culture medium was removed, and new medium containing freshly produced virus suspension was added to cover the surface of the wells (750 $\mu \mathrm{l} /$ well). After $4 \mathrm{~h}$ incubation at $37^{\circ} \mathrm{C}, 5 \% \mathrm{CO}_{2}$, additional medium was added ( $2 \mathrm{ml}$ total), and the cells were incubated overnight. The next day, the virus-containing medium was replaced by fresh culture medium. Medium was changed every day. Blasticidine $(2 \mu \mathrm{g} / \mathrm{ml})$ selection of transduced cells was started 4 days after transduction. To analyze functionality of the expression constructs, green fluorescence as well as Nkx2.2 expression of the transduced NSC was monitored after selection in blasticidine for 6-10 days. Based on EGFP expression, the transduction efficiency was $70 \pm 5 \%$ for the EGFP control virus and $65 \pm 5 \%$ for the $\mathrm{Nkx} 2.2 /$ EGFP virus. 


\section{Quantitative RT-PCR}

For RT-PCR, total RNA was extracted using the RNeasy kit (Qiagen, Hilden, Germany), and cDNA was generated using iScript (Bio-Rad, München). PCR was performed using an iCycler (Bio-Rad) with SYBR Green detection. For primers and conditions see Supplemental Materials and Methods.

\section{Results}

Generation of cell-permeant Nkx2.2 protein

For TAT-mediated protein transduction, a fusion protein composed of the TAT transduction domain and the $\mathrm{Nkx} 2.2$ protein was synthesized using a bacterial expression vector [17]. The recombinant Nkx2.2 fusion protein is composed of the transcription factor, a nuclear localization signal (NLS), the TAT protein transduction domain (TAT-PTD) and a histidine tag (Nkx2.2-NTH, Fig. 1a). The resulting Nkx2.2 fusion protein ( $35 \mathrm{kDa})$ could be efficiently purified by Ni-nitrilotriacetic acid chromatography from the bacterial expression system as shown by Coomassie blue staining as well as Western blot analysis using anti-5-histidine and anti-Nkx2.2 antibodies (Fig. 1b-d). The stability of the recombinant $\mathrm{Nkx} 2.2-\mathrm{NTH}$ protein in culture medium and at $37^{\circ} \mathrm{C}$ in the presence and absence of murine ESCderived NSC was confirmed by Western blot analysis (Fig. 1e). Nkx2.2 protein was detectable in medium up to $48 \mathrm{~h}$ both with and without cells. However, in the presence of NSC the majority of the protein disappeared from the medium after $48 \mathrm{~h}$, suggesting protein internalization and/ or degradation. Efficient protein transduction was confirmed by Western blot analysis of cell lysates from vehicle (glycerol)- or Nkx2.2-NTH-treated NSC (Fig. 1f). Whereas $\mathrm{Nkx} 2.2$ protein could not be detected in vehicle-treated cells, a time-dependent uptake was observed following Nkx2.2-NTH transduction. Intracellular protein degradation products could also be seen over time (arrows). Cellular uptake of the recombinant protein was also visualized by rhodamine labeling (Supplementary figure). Two hours following transduction of ESC-derived NSC, the labeled Nkx2.2 protein was localized in 'endosome-like' vesicles around the nucleus, suggesting protein uptake via the endosomal pathway [7, 30].

$\mathrm{Nkx} 2.2$ protein transduction promotes oligodendrocyte differentiation in differentiating NSC

We chose mouse ESC-derived NSC [42] for functional validation of recombinant transducible Nkx2.2-NTH. These cells exhibit endogenous expression of Olig2, Sox 10
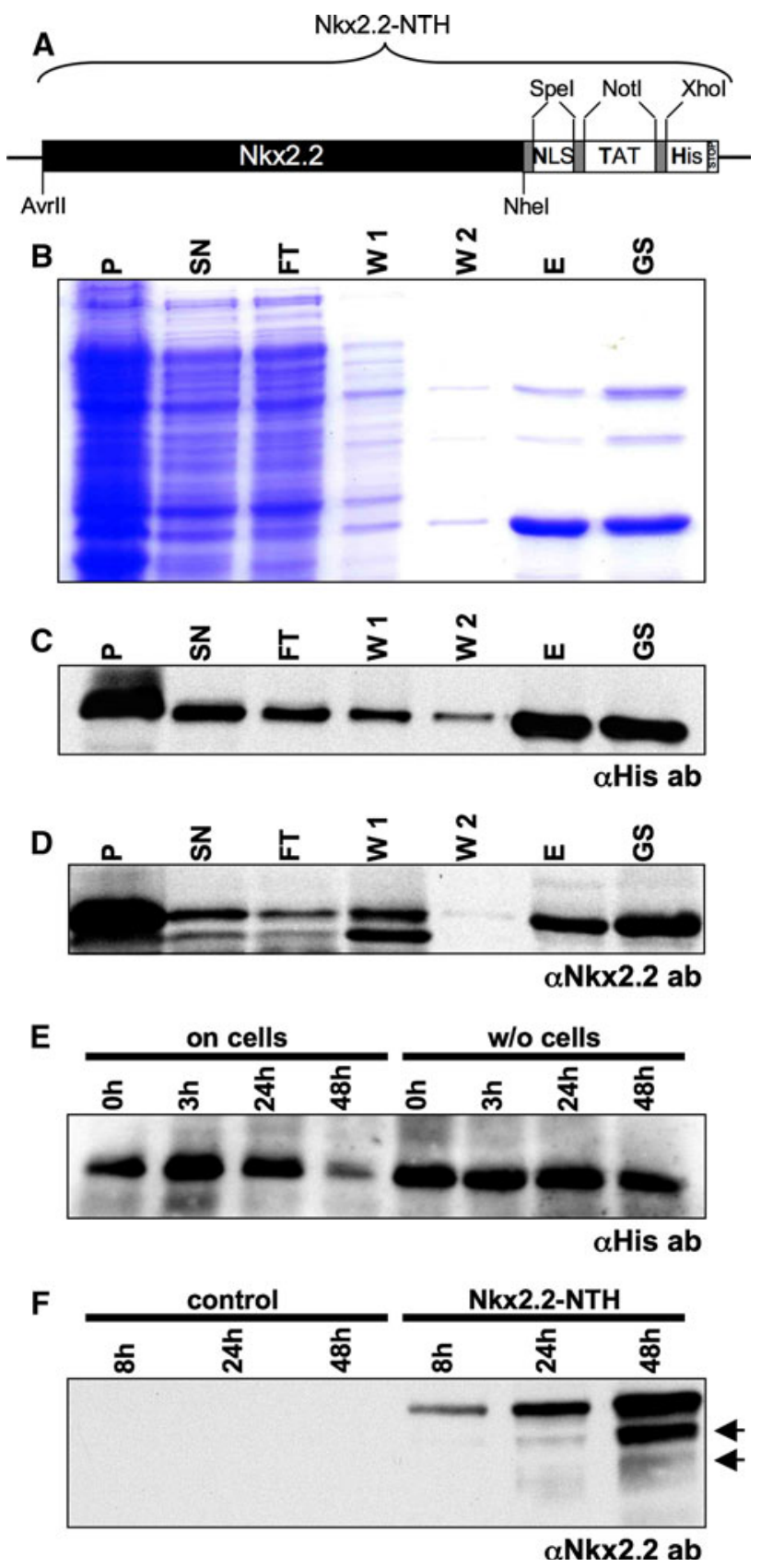

Fig. 1 Generation and purification of recombinant Nkx2.2-NTH protein. a Construction of the protein expression vector encoding the human Nkx2.2 in fusion with sequences encoding a nuclear localization signal (NLS), the TAT transactivator protein transduction domain to direct cellular uptake and a 6-histidine-tag (His) (Nkx2.2$\mathrm{NTH}$ ). Expression and purification of recombinant Nkx2.2 protein from bacteria was demonstrated by Coomassie blue staining of a SDS-PAGE (b) and Western Blot analysis using anti-Penta-His (c) and anti-Nkx2.2 antibodies (d). e Stability of the recombinant protein was analyzed under cell culture conditions in the presence and absence of NSC. f Protein uptake was assessed by Western blot analysis of cell lysates from vehicle (glycerol)- and Nkx2.2-NTHtransduced NSC at the indicated time points. Internalized protein was partly degraded over time (arrows). $P$ pellet, $S N$ supernatant, $F T$ flowthrough, $W 1$ washing fraction 1, W2 washing fraction 2, $E$ eluate, $G S$ glycerol stock 
Fig. 2 Baseline expression of gliogenic transcription factors in ESC-derived NSC. a Schematic representation of transcription factors that determine the neuron-glial switch and oligodendrocyte specification in the developing neural tube (adapted by permission from Macmillan Publishers Ltd. copyright 2004 [32]). b-e Immunofluorescence analysis revealed expression of the transcription factors Olig2, Sox 10 and Sox 9 in proliferating ESC-derived NSC. In contrast, individual cells expressed low levels of Nkx2.2. Scale bars b-e $50 \mu \mathrm{m}$
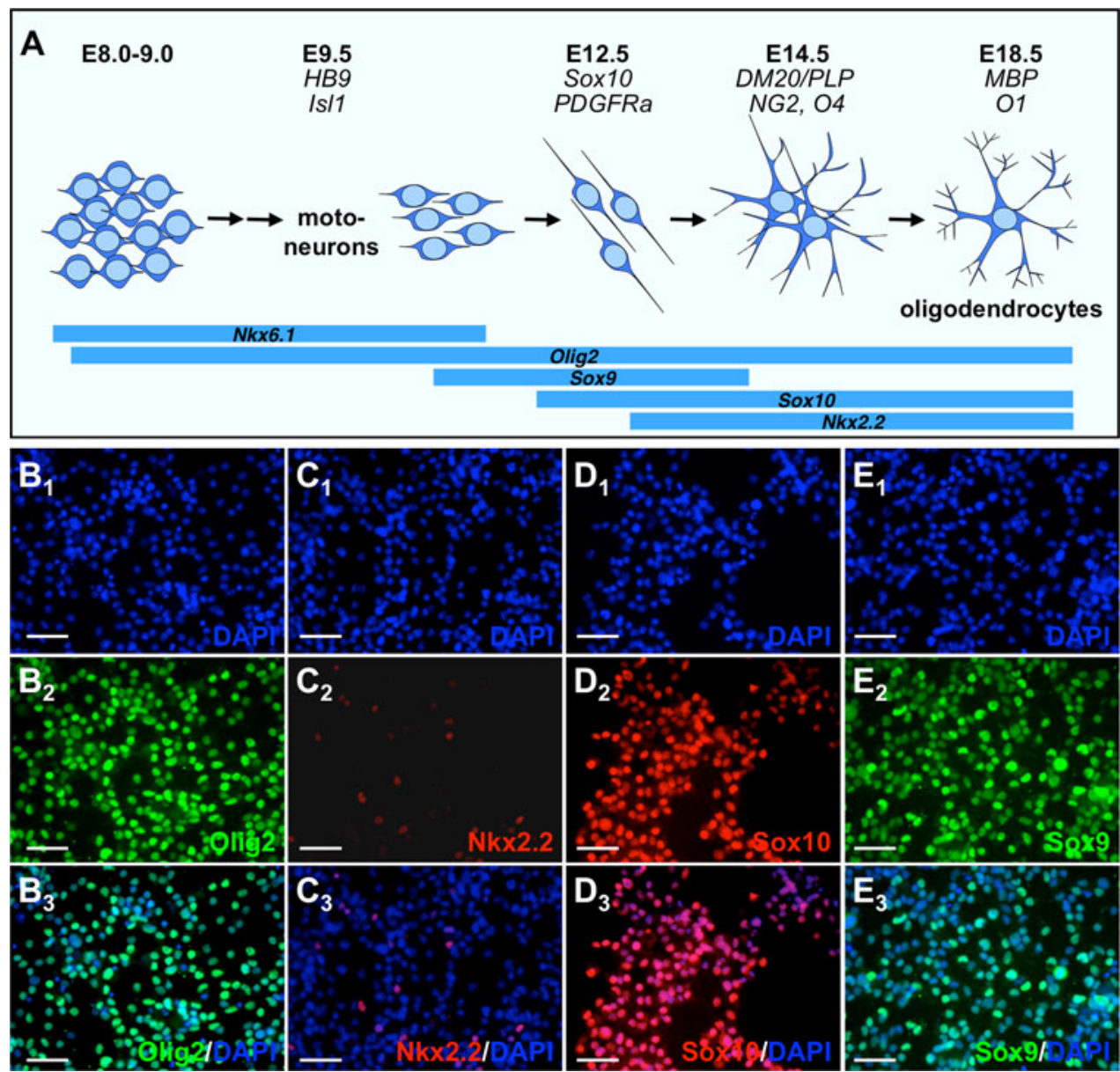

and Sox9, whereas Nkx2.2 expression is largely absent (Fig. 2b-e). The cells were grown on poly-L-ornithine/ laminin coated tissue culture dishes $\left(150,000\right.$ cells $\left./ \mathrm{cm}^{2}\right)$ and proliferated in expansion medium containing FGF2 and EGF (Fig. 3a). Oligodendroglial differentiation was induced by a 4-day growth factor withdrawal in the presence of $\mathrm{T} 3$ and ascorbic acid in differentiation medium [43]. Nkx2.2-NTH was added daily during the last day of proliferation in FGF2 and EGF and the subsequent 4-day differentiation period (Fig. 3b). Control populations were treated with glycerol buffer as vehicle only. Nkx2.2-NTH protein transduction resulted in a twofold increase in the number of oligodendrocytes expressing the $\mathrm{O} 4$ antigen as determined by immunofluorescence staining; $13.8 \pm 1.8 \%$ of Nkx2.2-transduced cultures expressed the oligodendrocyte-specific antigen (Fig. 3c, e), whereas control populations only gave rise to $7.4 \pm 0.6 \%$ O4-positive oligodendrocytes (Fig. 3d, e). In contrast, Nkx2.2 transduction yielded no significant changes in the number of cells expressing GFAP $(43.0 \pm 3.6 \%$, control: $44.1 \pm 2.5 \%)$ and $\beta$ III-tubulin $(28.4 \pm 8.1 \%$, control: $32.3 \pm 6.1 \%)$.
To study the dose dependency of Nkx2.2 transduction, NSC were exposed to different concentrations of the purified protein $(2,5,10,20 \mu \mathrm{g} / \mathrm{ml})$. To exclude an unspecific effect of protein transduction, cells were also treated with a TAT-Cre fusion protein [24]. The number of O4-positive oligodendrocytes peaked at $5 \mu \mathrm{g} / \mathrm{ml}$ and no further increase in oligodendrocyte differentiation and maturation was observed at higher concentrations (Fig. 3f). In contrast, the same concentrations of Cre protein had no effect on oligodendroglial differentiation compared to vehicle-treated control populations (not shown).

To determine changes in the expression of neural marker genes, total RNA was isolated after 1 day of proliferation and a 4-day growth factor withdrawal-induced differentiation from vehicle-treated control populations and cells treated with Nkx2.2-NTH. Quantitative RT-PCR demonstrated an increase in the expression of oligodendroglial marker genes following $\mathrm{Nkx} 2.2$ protein transduction compared to control cells (Fig. 3g). The early oligodendrocyte markers Sox 10 and NG2, but also genes typically expressed in mature oligodendrocytes such as CNP, PLP and MBP were upregulated in cells treated with the Nkx2.2 

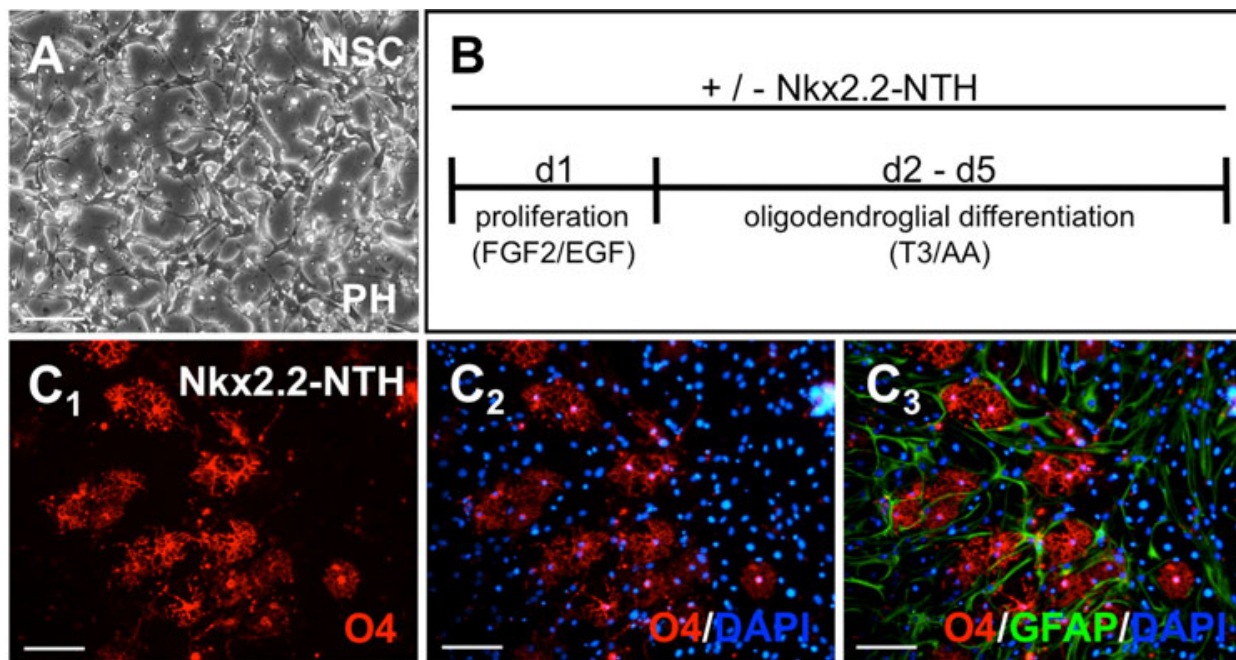
(FGF2/EGF) (T3/AA)
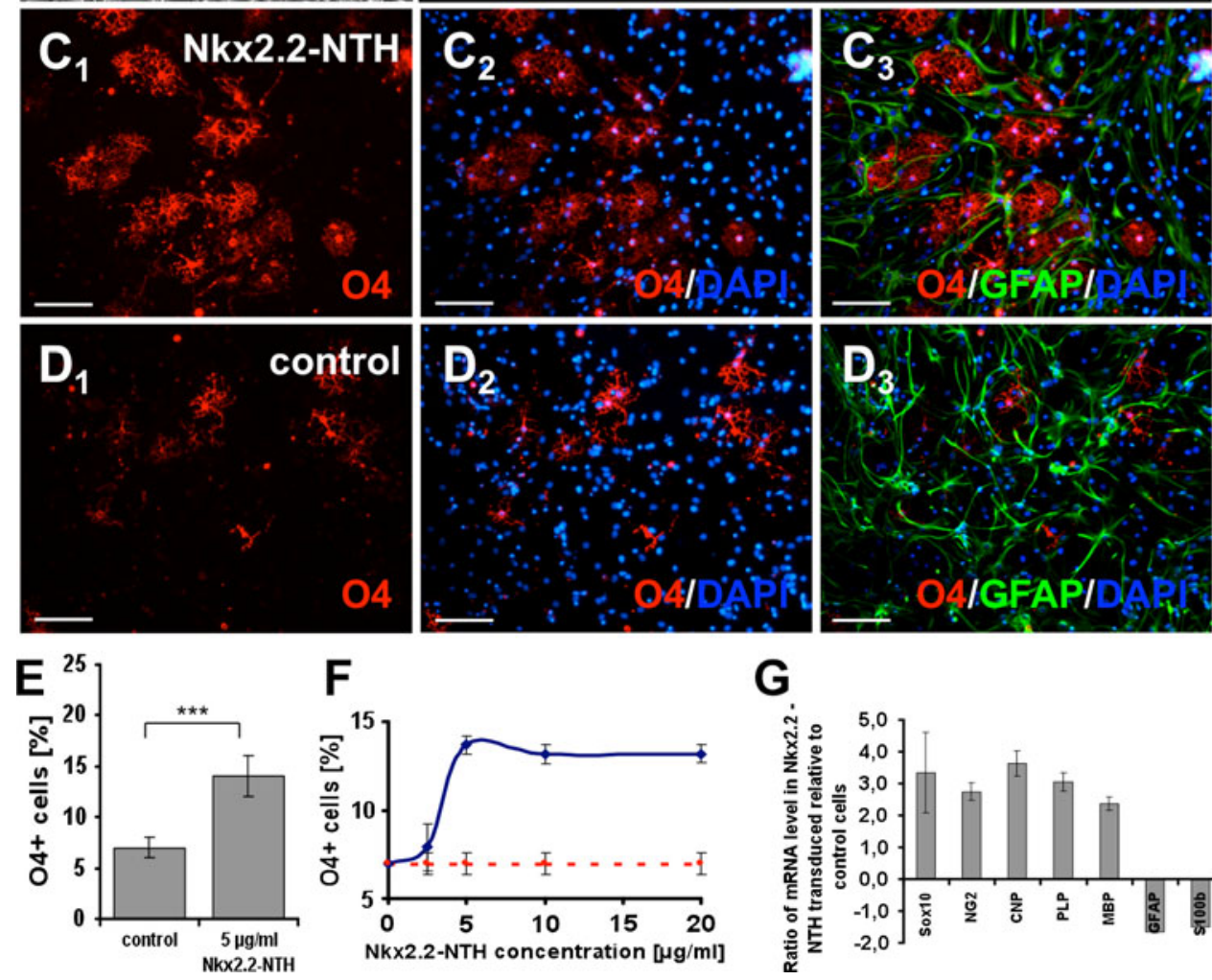

$\mathbf{F}$

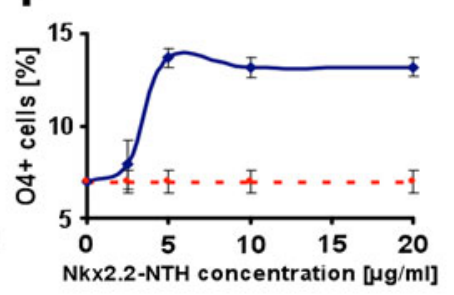

G

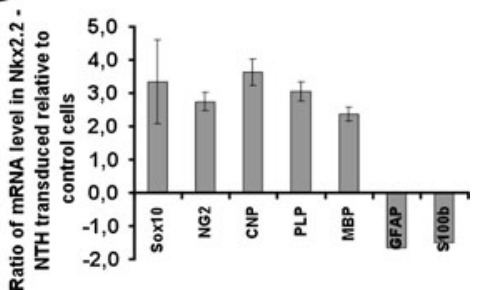

Fig. 3 Nkx2.2 protein transduction promotes oligodendrocyte differentiation in mouse ESC-derived NSC. Mouse ESC-derived NSC (a), largely negative for endogenous $\mathrm{Nkx} 2.2$, were induced to differentiate by growth factor withdrawal in the presence of $\mathrm{T} 3$ and ascorbic acid (AA) and incubated with recombinant $\mathrm{Nkx} 2.2$ protein $(5 \mu \mathrm{g} / \mathrm{ml} \mathrm{b})$. c-e After 5 days transduced populations showed a twofold increase of cells immunopositive for the oligodendrocyte-specific O4 antigen (Nkx 2.2: $13.8 \pm 1.8 \%$, vehicle control: $7.4 \pm 0.6 \%$; mean $\pm \mathrm{SD}$ ). $* * * P<0.001$ (Student's $t$ test). f Concentration-dependent effect of Nkx2.2-NTH transduction on mouse ESC-derived NSC. A twofold increase in the number of O4-positive oligodendrocytes (blue curve)

protein. This was not the case for the astrocytic markers GFAP and S100ß, which were even slightly decreased. Together, our RT-PCR data confirmed a promotion of oligodendroglial differentiation following Nkx2.2 protein transduction as observed in the immunocytochemical studies.

Enhanced oligodendroglial differentiation was also reflected by changes in morphology. Nkx2.2-transduced cultures yielded more oligodendrocytes with a complex, mature phenotype. Specifically, oligodendrocytes in compared to vehicle-treated control cells (red dashed line) could be detected already with $5 \mu \mathrm{g} / \mathrm{ml}$ protein. Higher concentrations had no further effect on oligodendroglial differentiation (mean $\pm \mathrm{SD}$ ). g Quantitative RT-PCR analysis of neural marker genes in differentiated cultures of $\mathrm{Nkx} 2.2-\mathrm{NTH}$-transduced NSC relative to control populations. $\mathrm{Nkx} 2.2$ transduction resulted in an increase in transcripts for early (sox10, ng2) and advanced (cnp, plp, mbp) oligodendroglial differentiation, whereas astrocytic markers $(g f a p, s 100 \beta)$ were slightly decreased (mean \pm SEM). DAPI was used for nuclear counterstaining (blue). Scale bars $\mathbf{a}, \mathbf{c}, \mathbf{d} 50 \mu \mathrm{m}$

Nkx2.2-transduced cultures exhibited ramified multipolar processes (Fig. 4a), whereas O4-positive cells in control populations typically adopted a bipolar or poorly branched phenotype (Fig. 4b). In mature oligodendrocytes, the main processes typically branch into secondary and tertiary processes. To analyze the effect on maturation in more detail, the ramification of oligodendrocyte processes was quantified. Nkx2.2-NTH protein transduction resulted in more oligodendrocytes with a tertiary ramified phenotype, suggesting a shift from immature to more mature 
oligodendrocytes. Using these criteria for morphological maturity, $66.7 \pm 3.1 \%$ of the oligodendrocytes in the controls were immature, and $33.3 \pm 3.1 \%$ showed a mature phenotype. In contrast, Nkx2.2-NTH treatment resulted in only $11.7 \pm 3.8 \%$ immature and $88.3 \pm 3.8 \%$ mature oligodendrocytes (Fig. 4c). In addition, oligodendrocytes in Nkx2.2-transduced cultures but not control populations exhibited prominent myelin-like membrane sheet extensions (Fig. 4d). No differences in the total number of cells immunopositive for the early oligodendrocyte marker NG2 could be observed between Nkx2.2treated and control populations $(\mathrm{Nkx} 2.217 .2 \pm 4.9 \%$, control: $18.0 \pm 4.0 \%$; Fig. $4 \mathrm{e}$, f). However, in Nkx2.2transduced populations many NG2-positive cells had already initiated expression of $\mathrm{O} 4$ (Fig. 4e). In contrast, the majority of NG2-positive cells in control cultures displayed a bipolar phenotype of pre-oligodendrocytes still negative for $\mathrm{O} 4$ expression (Fig. 4f). Specifically, $9.6 \pm 2.2 \%$ of the Nkx2.2-transduced cells, but only $1.7 \pm 1.5 \%$ of the control cells co-expressed NG2 and $\mathrm{O} 4$ (Fig. 4g).

Taken together, these data indicate that direct delivery of the oligodendroglial transcription factor $\mathrm{Nkx} 2.2$ by protein transduction promotes oligodendroglial maturation in ESC-derived NSC cultures.

\section{Differentiation effect of Nkx2.2 protein transduction is comparable to lentiviral gene transfer}

In order to evaluate how the non-genetic transduction of Nkx2.2 compares to viral transduction in terms of efficacy, we also used lentiviral vectors to generate Nkx2.2overexpressing NSC and EGFP-expressing control cells (Fig. 5a-c). Following virus transduction, ESC-derived NSC were selected with blasticidine for at least 610 days. Transgene expression was confirmed by immunofluorescence analysis of Nkx2.2 and EGFP expression. The transgenic NSC were differentiated according to the conditions used for protein transduction, i.e., proliferation for 1 day in expansion medium containing FGF2 and EGF and differentiation by growth factor withdrawal in the presence of T3 and ascorbic acid for 4 days in differentiation medium. Similar to $\mathrm{Nkx} 2.2$ protein transduction, stable overexpression of $\mathrm{Nkx} 2.2$ resulted in a twofold increase in oligodendrocytes expressing the $\mathrm{O} 4$ antigen in differentiated cultures (Fig. 5d-g). While only $6.4 \pm 1.2 \%$ of the cells infected with control virus showed O4 immunoreactivity, $12.2 \pm 2.1 \%$ of the NSC stably overexpressing Nkx2.2 generated O4-positive oligodendrocytes. As observed after Nkx2.2-NTH protein transduction, the $\mathrm{Nkx} 2.2$-overexpressing cultures contained oligodendroglial cells with a more ramified, mature phenotype compared to EGFP-expressing control cells as
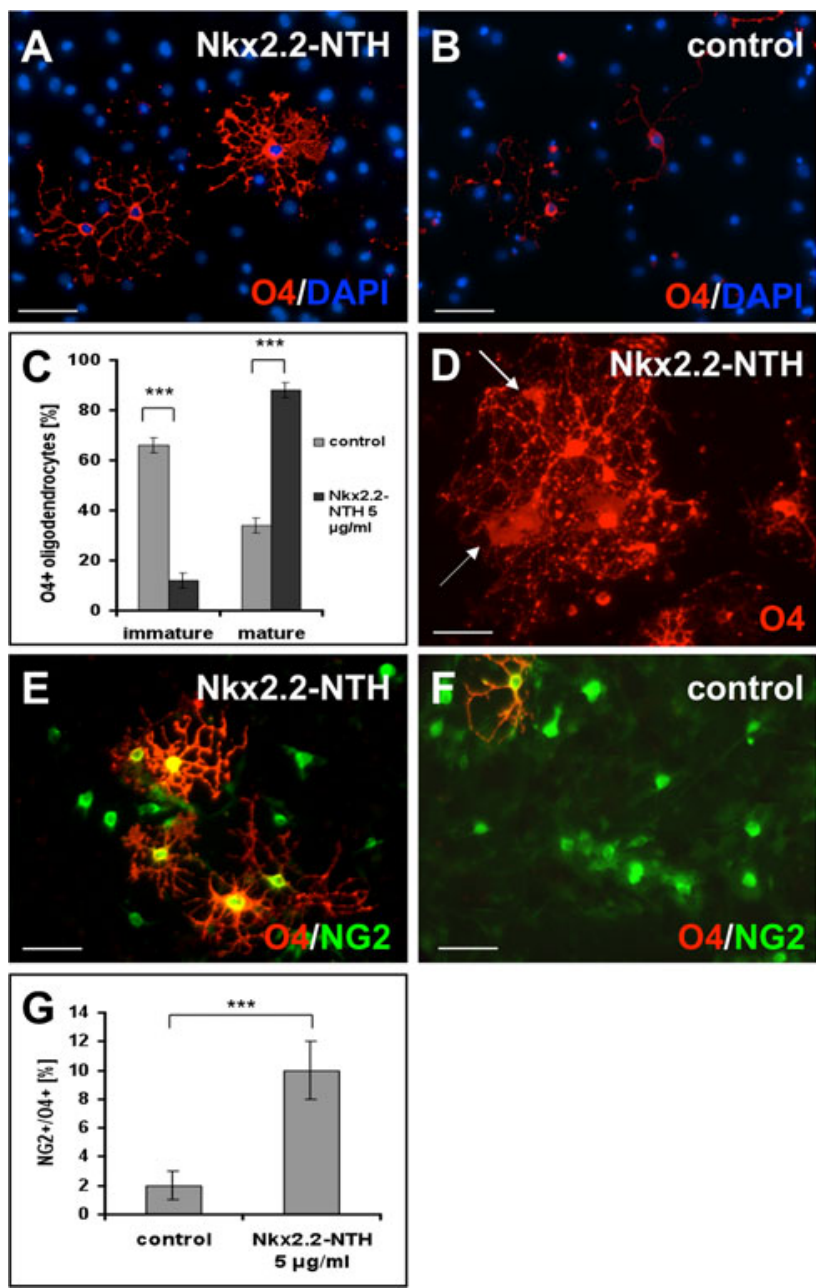

Fig. $4 \mathrm{Nkx} 2.2$ protein transduction promotes oligodendrocyte maturation in mouse ESC-derived NSC. a, b Immunofluorescence analysis of the $\mathrm{O} 4$ antigen reveals differences in morphological maturation between Nkx2.2-transduced and control oligodendrocytes. c Quantification of oligodendrocyte maturation. Oligodendrocytes with three or more branches were classified as mature. Nkx2.2transduced NSC generated more oligodendrocytes with a mature, tertiary ramified phenotype compared to control cells. d Oligodendrocytes generated from Nkx2.2-transduced NSC formed myelin sheath-like membrane protrusions (arrows). e, f Immunostaining for the early oligodendroglial marker NG2 and O4 confirmed the differences in the developmental stages of oligodendrocytes in Nkx2.2-transduced and control populations. g Quantitative analysis of cells co-expressing NG2 and $\mathrm{O} 4$. The majority of NG2-positive oligodendrocytes in the control population represented pre-oligodendrocytes, which could not be stained for the oligodendrocyte marker O4. Shown are mean values $\pm \mathrm{SD}$. $* * * P<0.001$ (Student's $t$ test). DAPI was used for nuclear counterstaining (blue). Scale bars $\mathbf{a}, \mathbf{b}, \mathbf{e}$, f $25 \mu \mathrm{m}, \mathbf{d} 10 \mu \mathrm{m}$

shown by $\mathrm{O} 4$ and NG2 immunostaining (Fig. 5f, g). Thus, with respect to promoting oligodendroglial differentiation of ESC-derived NSC, Nkx2.2 protein transduction appears to compete well with lentiviral transduction of this transcription factor. 


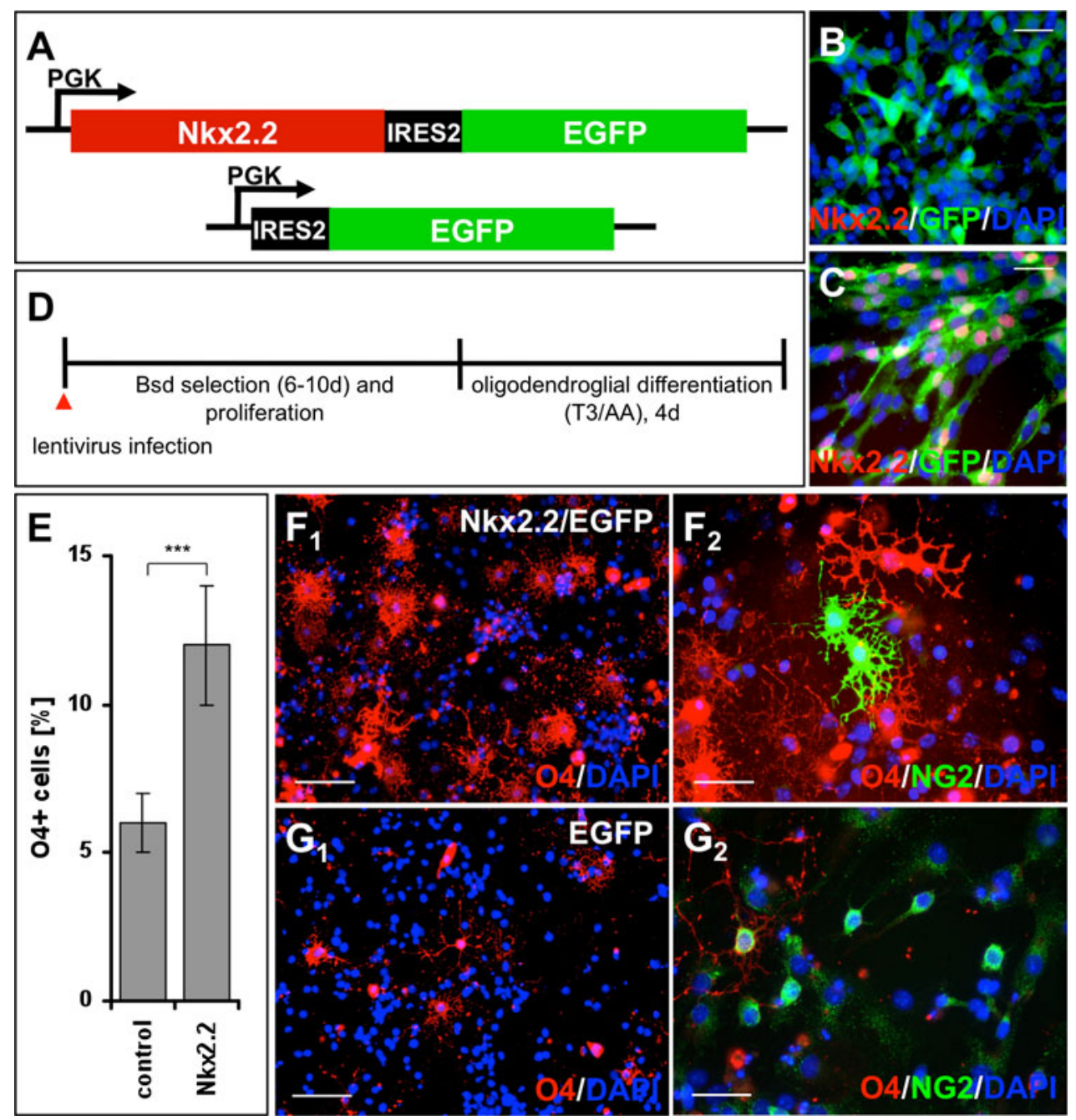

Fig. 5 Effects of Nkx2.2 protein transduction on oligodendrocyte differentiation and maturation are comparable to lentiviral-mediated gene transfer. a NSC derived from ESC were transduced with EGFPand Nkx2.2/EGFP-expressing lentiviruses (pPGK-IRES2-EGFP, pPGK-Nkx2.2-IRES2-EGFP). Transgene expression in EGFP- (b) and Nkx2.2/EGFP-transduced cells (c) was confirmed by immunofluorescence analysis using anti-EGFP and anti-Nkx2.2 antibodies. d Infected cells were selected with blasticidine (Bsd) for 6-10 days before they were differentiated. Following a 4-day growth factormediated differentiation in the presence of $\mathrm{T} 3$ and $\mathrm{AA}$, cultures of Nkx2.2-overexpressing cells contained more oligodendrocytes

\section{Discussion}

The results of this study show that direct transduction of the gliogenic transcription factor Nkx2.2 as TAT fusion protein promotes differentiation into an oligodendrocytic phenotype in differentiating ESC-derived NSC. Under cell culture conditions, the purified fusion protein is stable for at least $24 \mathrm{~h}$. When added to cultures of ESC-derived NSC, the protein was efficiently taken up by the cells as determined by Western blot analysis of cell lysates and uptake studies using rhodamine-labeled protein. Moreover, the fusion protein positive for the $\mathrm{O} 4$ antigen (EGFP control: $6.4 \pm 1.2 \%$; Nkx2.2: $12.2 \pm 2.1 \%$; mean $\pm \mathrm{SD}, * * * P<0.001$, Student's $t$ test). Oligodendrocytes in cultures stably overexpressing Nkx2.2 also adopted a more ramified mature phenotype compared to EGFP-expressing control cells (f, g). NG2 immunostaining revealed the generation of oligodendrocytes with complex ramified processes in Nkx2.2-transduced cultures $\left(\mathbf{f}_{2}\right)$, whereas control populations predominantly exhibited NG2-positive pre-oligodendrocytes $\left(\mathbf{g}_{2}\right)$. DAPI was used for nuclear counterstaining (blue). Scale bars b, c $50 \mu \mathrm{m}, \mathbf{f}_{\mathbf{1}}, \mathbf{g}_{\mathbf{1}}$ $50 \mu \mathrm{m}, \mathbf{f}_{2}, \mathbf{g}_{2} 25 \mu \mathrm{m}$

elicits a clear effect on the generation and maturation of oligodendrocytes in differentiated cultures of ESC-derived NSC. These cells were previously shown to exhibit tripotential differentiation into neurons and glia with expression of the oligodendrocyte-specific O4 antigen in up to $20 \%$ of the cells under appropriate culture conditions, i.e., proliferation in FGF2, PDGF and Forskolin for 4 days to promote the generation of oligodendrocyte progenitor cells followed by growth factor withdrawal-induced terminal differentiation [43]. However, for the current study NSC were directly differentiated without the 4-day proliferation step in FGF2/ 
PDGF/Forskolin. Since these conditions usually generate very low numbers of oligodendrocytes $(<10 \%)$, we considered them particularly suitable for assessing a potential prooligodendrogliogenic effect of the Nkx2.2-NTH fusion protein in this proof-of-concept study. Indeed, following protein transduction, the number of O4-positive oligodendrocytes observed after 4 days of in vitro differentiation of ESC-derived NSC was doubled. Furthermore, oligodendrocytes emerging from Nkx2.2-NTH-treated cultures showed a more mature phenotype with highly branched processes and formation of myelin-like membrane sheet extensions. Similar results could be obtained by comparative studies following viral gene transfer. These data indicate that (1) direct intracellular delivery of transcription factors can be used to modulate lineage differentiation in NSC cultures, and (2) protein transduction is comparable to genetic modification in governing transcription factor-based biological effects. However, with Nkx2.2 protein or gene transfer ESCderived NSC still produce not more than $\sim 20 \%$ O4-positive oligodendrocytes, a number these cells were also able to generate following propagation in FGF2/PDGF [43], suggesting saturation at this point. Considering transcriptional activation by growth factor-mediated signaling pathways, similar mechanisms could be involved in both, the proliferation step in FGF2/PDGF and Nkx2.2 expression.

In principle, the effect of $\mathrm{Nkx} 2.2$ protein transduction could be due to a general shift in lineage differentiation and/or an acceleration of oligodendrocyte maturation. However, there is evidence that $\mathrm{Nkx} 2.2$ seems to be more relevant at later stages for promoting oligodendrocyte maturation, rather than for the specification of oligodendrocyte progenitors [32]. Indeed, while Nkx2.2 transduction of ESC-derived NSC resulted in a twofold increase in the number of O4-positive oligodendrocytes, no differences in the number of NG2-positive early pre-oligodendrocytes could be observed between $\mathrm{Nkx} 2.2$ transduced and control populations. In addition, oligodendrocytes of $\mathrm{Nkx}$ 2.2-transduced cultures exhibited a more mature, ramified morphology and formed myelin-like membrane sheet extensions. Results from quantitative PCR analysis confirmed an increase in the expression of myelinspecific markers typically expressed in mature oligodendrocytes, such as CNP, PLP and MBP. Thus, our data support the notion that $\mathrm{Nkx} 2.2$ protein transduction induces oligodendrocyte maturation rather than a general change in lineage commitment.

Protein transduction: an emerging tool for non-genetic stem cell engineering

Forced expression of lineage specific transcription factors has been shown to enhance induction of well-defined neural lineages in embryonic and adult stem cells [1-3,
37-41, 44]. However, the efficiency of DNA transfection technologies is highly variable among different cell types and can be low in primary cells, stem cells and tumor cells. The utility of viral vectors is limited by DNA carrying capacity, difficulty in reliable and cost-effective manufacturing and safety concerns such as random integration. Other methods of delivering recombinant DNA into the cell, such as lipofection and electroporation, suffer from variable efficiency or severely compromise cellular viability. In contrast, protein transduction allows the direct delivery of proteins into mammalian cells both in vitro and in vivo without genetic manipulation [6, 8, 14, 45, 46]. Specifically, protein transduction of transcription factors could provide sufficient stimulus for initiating a specific cell fate while allowing a precise control of dose, onset and length of expression. Noguchi et al. showed that recombinant pancreatic and duodenal homeobox transcription factor-1 (PDX-1) protein can permeate pancreatic cells due to an endogenous, antennapedia-like PTD and functions similarly to endogenous PDX-1 by stimulating insulin gene expression [47]. Similarly, TAT-PDX-1 protein transduced into human ESC is able to induce insulin protein production by activation of its downstream target genes [48]. In addition to cell fate specification, protein transduction could also be used to maintain a certain multipotent precursor population by providing the required protein. In such a way the recombinant form of the homeobox transcription factor HOXB4 (TAT-HOXB4) was used to proliferate hematopoietic stem cells in vitro, making it a potential candidate for therapeutic stem cell expansion [19]. Very recently, it has been shown that protein transduction may also be used for delivering reprogramming factors into somatic cells [17, 20, 21].

Here, we demonstrate that protein transduction is as efficient as virus-mediated gene transfer in transcription factor-based promotion of NSC differentiation. Thus, protein transduction technology has the potential to become an efficient alternative to genetic modification while allowing temporal and reversible regulation of biological processes.

The results of our study show that $48 \mathrm{~h}$ after application a large fraction of the fusion protein can still be detected in the transduced cells (Fig. 1f). This time window should be sufficiently broad to also permit simultaneous application of several recombinant transcription factors, which cooperate in cell fate determination. Alternatively, cell-permeant transcription factors might be applied sequentially to mimic successive transcription factor expression cascades observed during normal development. Another advantage is that individual cell-permeant proteins can be administered in a titratable fashion as has been demonstrated in previous work with TAT-Cre fusion proteins in both mouse and human cells [24, 49]. Thus, protein transduction offers a series of advantages, which cannot be easily achieved using 
conventional gene-based methods. Considering that transplantation of ESC derived oligodendrocytes has been successfully applied for myelin repair in vivo [50, 51], the approach presented here should also contribute to further optimization of donor cell preparation for glial cell transplantation. Beyond its use for modulating in vitro stem cell differentiation, protein transduction might also be applied in vivo. For example, in a recent study intravenous injection of a TAT-Bcl- $x_{L}$ fusion protein has been shown to improve survival of neuronal precursor cells in the lesioned striatum after focal cerebral ischemia [52]. In conclusion, protein transduction of recombinant transcription factors could develop into an attractive tool to modulate differentiation and promote survival of resident and cultured stem and progenitor cells without genetic modification.

Acknowledgments We thank Austin Smith, Steve Pollard, Luciano Conti and Elena Cattaneo for the NS-5 cells and Claudia Schwarz for excellent technical help. We are grateful to all members of the Stem Cell Engineering Group for their support relating to protein purification. This study was supported by grants from the German Bundesministerium für Bildung und Forschung (BMBF; Grant no. 01GN0502), the Helga Ravenstein Foundation and the Hertie Foundation.

Open Access This article is distributed under the terms of the Creative Commons Attribution Noncommercial License which permits any noncommercial use, distribution, and reproduction in any medium, provided the original author(s) and source are credited.

\section{References}

1. Kim DW, Chung S, Hwang M, Ferree A, Tsai HC, Park JJ, Nam TS, Kang UJ, Isacson O, Kim KS (2006) Stromal cell-derived inducing activity, Nurr1, and signaling molecules synergistically induce dopaminergic neurons from mouse embryonic stem cells. Stem Cells 24:557-567

2. Andersson E, Tryggvason U, Deng Q, Friling S, Alekseenko Z, Robert B, Perlmann T, Ericson J (2006) Identification of intrinsic determinants of midbrain dopamine neurons. Cell 124:393-405

3. Chung S, Sonntag KC, Andersson T, Bjorklund LM, Park JJ, Kim DW, Kang UJ, Isacson O, Kim KS (2002) Genetic engineering of mouse embryonic stem cells by Nurr1 enhances differentiation and maturation into dopaminergic neurons. Eur J Neurosci 16:1829-1838

4. Gump JM, Dowdy SF (2007) TAT transduction: the molecular mechanism and therapeutic prospects. Trends Mol Med 13:443448

5. Dietz GP, Bahr M (2007) Synthesis of cell-penetrating peptides and their application in neurobiology. Methods Mol Biol 399:181-198

6. Dietz GP, Bahr M (2004) Delivery of bioactive molecules into the cell: the Trojan horse approach. Mol Cell Neurosci 27:85-131

7. Wadia JS, Stan RV, Dowdy SF (2004) Transducible TAT-HA fusogenic peptide enhances escape of TAT-fusion proteins after lipid raft macropinocytosis. Nat Med 10:310-315

8. Schwarze SR, Ho A, Vocero-Akbani A, Dowdy SF (1999) In vivo protein transduction: delivery of a biologically active protein into the mouse. Science 285:1569-1572
9. Fawell S, Seery J, Daikh Y, Moore C, Chen LL, Pepinsky B, Barsoum J (1994) Tat-mediated delivery of heterologous proteins into cells. Proc Natl Acad Sci USA 91:664-668

10. Elliott G, O'Hare P (1997) Intercellular trafficking and protein delivery by a herpesvirus structural protein. Cell 88:223-233

11. Derossi D, Joliot AH, Chassaing G, Prochiantz A (1994) The third helix of the antennapedia homeodomain translocates through biological membranes. J Biol Chem 269:10444-10450

12. Joliot A, Pernelle C, Deagostini-Bazin H, Prochiantz A (1991) Antennapedia homeobox peptide regulates neural morphogenesis. Proc Natl Acad Sci USA 88:1864-1868

13. Snyder EL, Meade BR, Saenz CC, Dowdy SF (2004) Treatment of terminal peritoneal carcinomatosis by a transducible p53activating peptide. PLoS Biol 2:E36

14. Nagahara H, Vocero-Akbani AM, Snyder EL, Ho A, Latham DG, Lissy NA, Becker-Hapak M, Ezhevsky SA, Dowdy SF (1998) Transduction of full-length TAT fusion proteins into mammalian cells: TAT-p27Kip1 induces cell migration. Nat Med 4:14491452

15. Peitz M, Pfannkuche K, Rajewsky K, Edenhofer F (2002) Ability of the hydrophobic FGF and basic TAT peptides to promote cellular uptake of recombinant Cre recombinase: a tool for efficient genetic engineering of mammalian genomes. Proc Natl Acad Sci USA 99:4489-4494

16. Jo D, Nashabi A, Doxsee C, Lin Q, Unutmaz D, Chen J, Ruley HE (2001) Epigenetic regulation of gene structure and function with a cell-permeable Cre recombinase. Nat Biotechnol 19:929-933

17. Bosnali M, Edenhofer F (2008) Generation of transducible versions of transcription factors Oct4 and Sox2. Biol Chem 389:851861

18. Landry JR, Kinston S, Knezevic K, de Bruijn MF, Wilson N, Nottingham WT, Peitz M, Edenhofer F, Pimanda JE, Ottersbach $\mathrm{K}$, Gottgens B (2008) Runx genes are direct targets of Scl/Tal1 in the yolk sac and fetal liver. Blood 111:3005-3014

19. Krosl J, Austin P, Beslu N, Kroon E, Humphries RK, Sauvageau $G$ (2003) In vitro expansion of hematopoietic stem cells by recombinant TAT-HOXB4 protein. Nat Med 9:1428-1432

20. Zhou H, Wu S, Joo JY, Zhu S, Han DW, Lin T, Trauger S, Bien G, Yao S, Zhu Y, Siuzdak G, Scholer HR, Duan L, Ding S (2009) Generation of induced pluripotent stem cells using recombinant proteins. Cell Stem Cell 4:381-384

21. Kim D, Kim CH, Moon JI, Chung YG, Chang MY, Han BS, Ko S, Yang E, Cha KY, Lanza R, Kim KS (2009) Generation of human induced pluripotent stem cells by direct delivery of reprogramming proteins. Cell Stem Cell 4:472-476

22. Peitz M, Jager R, Patsch C, Jager A, Egert A, Schorle H, Edenhofer F (2007) Enhanced purification of cell-permeant Cre and germline transmission after transduction into mouse embryonic stem cells. Genesis 45:508-517

23. Nolden L, Edenhofer F, Haupt S, Koch P, Wunderlich FT, Siemen H, Brustle O (2006) Site-specific recombination in human embryonic stem cells induced by cell-permeant Cre recombinase. Nat Methods 3:461-467

24. Haupt S, Edenhofer F, Peitz M, Leinhaas A, Brustle O (2007) Stage-specific conditional mutagenesis in mouse embryonic stem cell-derived neural cells and postmitotic neurons by direct delivery of biologically active Cre recombinase. Stem Cells 25:181-188

25. Cao G, Pei W, Ge H, Liang Q, Luo Y, Sharp FR, Lu A, Ran R, Graham SH, Chen J (2002) In vivo delivery of a Bcl-xL fusion protein containing the TAT protein transduction domain protects against ischemic brain injury and neuronal apoptosis. J Neurosci 22:5423-5431

26. Ohta Y, Kamiya T, Nagai M, Nagata T, Morimoto N, Miyazaki K, Murakami T, Kurata T, Takehisa Y, Ikeda Y, Asoh S, Ohta S, Abe K (2008) Therapeutic benefits of intrathecal protein therapy 
in a mouse model of amyotrophic lateral sclerosis. J Neurosci Res 86:3028-3037

27. Kilic E, Kilic U, Hermann DM (2006) TAT fusion proteins against ischemic stroke: current status and future perspectives. Front Biosci 11:1716-1721

28. Kilic E, Kilic U, Hermann DM (2005) TAT-GDNF in neurodegeneration and ischemic stroke. CNS Drug Rev 11:369-378

29. Choi HS, Lee SH, Kim SY, An JJ, Hwang SI, Kim DW, Yoo KY, Won MH, Kang TC, Kwon HJ, Kang JH, Cho SW, Kwon OS, Choi JH, Park J, Eum WS, Choi SY (2006) Transduced Tatalpha-synuclein protects against oxidative stress in vitro and in vivo. J Biochem Mol Biol 39:253-262

30. Tunnemann G, Martin RM, Haupt S, Patsch C, Edenhofer F, Cardoso MC (2006) Cargo-dependent mode of uptake and bioavailability of TAT-containing proteins and peptides in living cells. FASEB J 20:1775-1784

31. Edenhofer F (2008) Protein transduction revisited: novel insights into the mechanism underlying intracellular delivery of proteins. Curr Pharm Des 14:3628-3636

32. Rowitch DH (2004) Glial specification in the vertebrate neural tube. Nat Rev Neurosci 5:409-419

33. Zhou Q, Anderson DJ (2002) The bHLH transcription factors OLIG2 and OLIG1 couple neuronal and glial subtype specification. Cell 109:61-73

34. Takebayashi H, Nabeshima Y, Yoshida S, Chisaka O, Ikenaka K (2002) The basic helix-loop-helix factor olig2 is essential for the development of motoneuron and oligodendrocyte lineages. Curr Biol 12:1157-1163

35. Lu QR, Sun T, Zhu Z, Ma N, Garcia M, Stiles CD, Rowitch DH (2002) Common developmental requirement for Olig function indicates a motor neuron/oligodendrocyte connection. Cell 109:75-86

36. Stolt CC, Rehberg S, Ader M, Lommes P, Riethmacher D, Schachner M, Bartsch U, Wegner M (2002) Terminal differentiation of myelin-forming oligodendrocytes depends on the transcription factor Sox10. Genes Dev 16:165-170

37. Qi Y, Cai J, Wu Y, Wu R, Lee J, Fu H, Rao M, Sussel L, Rubenstein J, Qiu M (2001) Control of oligodendrocyte differentiation by the Nkx2.2 homeodomain transcription factor. Development 128:2723-2733

38. Zhou Q, Choi G, Anderson DJ (2001) The bHLH transcription factor Olig2 promotes oligodendrocyte differentiation in collaboration with $\mathrm{Nkx} 2.2$. Neuron 31:791-807

39. Du ZW, Li XJ, Nguyen GD, Zhang SC (2006) Induced expression of Olig2 is sufficient for oligodendrocyte specification but not for motoneuron specification and astrocyte repression. Mol Cell Neurosci 33:371-380

40. Maire CL, Buchet D, Kerninon C, Deboux C, Baron-Van Evercooren A, Nait-Oumesmar B (2009) Directing human neural stem/precursor cells into oligodendrocytes by overexpression of Olig2 transcription factor. J Neurosci Res 15:3438-3446

41. Zhang X, Cai J, Klueber KM, Guo Z, Lu C, Qiu M, Roisen FJ (2005) Induction of oligodendrocytes from adult human olfactory epithelial-derived progenitors by transcription factors. Stem Cells 23:442-453

42. Conti L, Pollard SM, Gorba T, Reitano E, Toselli M, Biella G, Sun Y, Sanzone S, Ying QL, Cattaneo E, Smith A (2005) Nicheindependent symmetrical self-renewal of a mammalian tissue stem cell. PLoS Biol 3:e283

43. Glaser T, Pollard SM, Smith A, Brustle O (2007) Tripotential differentiation of adherently expandable neural stem (NS) cells. PLOS ONE 2:e298

44. Xian H, Gottlieb DI (2004) Dividing Olig2-expressing progenitor cells derived from ES cells. Glia 47:88-101

45. Schwarze SR, Dowdy SF (2000) In vivo protein transduction: intracellular delivery of biologically active proteins, compounds and DNA. Trends Pharmacol Sci 21:45-48

46. Wadia JS, Dowdy SF (2002) Protein transduction technology. Curr Opin Biotechnol 13:52-56

47. Noguchi H, Kaneto H, Weir GC, Bonner-Weir S (2003) PDX-1 protein containing its own antennapedia-like protein transduction domain can transduce pancreatic duct and islet cells. Diabetes 52:1732-1737

48. Kwon YD, Oh SK, Kim HS, Ku SY, Kim SH, Choi YM, Moon SY (2005) Cellular manipulation of human embryonic stem cells by TAT-PDX1 protein transduction. Mol Ther 12:28-32

49. Nolden L, Edenhofer F, Peitz M, Brustle O (2007) Stem cell engineering using transducible Cre recombinase. Methods Mol Med 140:17-32

50. Brustle O, Jones KN, Learish RD, Karram K, Choudhary K, Wiestler OD, Duncan ID, McKay RD (1999) Embryonic stem cell-derived glial precursors: a source of myelinating transplants. Science 285:754-756

51. Glaser T, Perez-Bouza A, Klein K, Brustle O (2005) Generation of purified oligodendrocyte progenitors from embryonic stem cells. FASEB J 19:112-114

52. Doeppner TR, Dietz GP, El Aanbouri M, Gerber J, Witte OW, Bahr M, Weise J (2009) TAT-Bcl-x(L) improves survival of neuronal precursor cells in the lesioned striatum after focal cerebral ischemia. Neurobiol Dis 34:87-94 